\title{
How Should the Psychological Well-Being of Zoo Elephants be Objectively Investigated?
}

\author{
Georgia J. Mason ${ }^{1 *}$ and Jake S. Veasey ${ }^{2}$ \\ ${ }^{1}$ Canada Research Chair in Animal Welfare, Animal Science Department, \\ University of Guelph, Guelph, Ontario, Canada \\ ${ }^{2}$ Department of Animal Management and Conservation, Woburn Safari Park, \\ Woburn, Bedfordshire, United Kingdom
}

\begin{abstract}
Animal welfare (sometimes termed "well-being") is about feelings - states such as "suffering" or "contentment" that we can infer but cannot measure directly. Welfare indices have been developed from two main sources: studies of suffering humans, and of research animals deliberately subjected to challenges known to affect emotional state. We briefly review the resulting indices here, and discuss how well they are understood for elephants, since objective welfare assessment should play a central role in evidence-based elephant management. We cover behavioral and cognitive responses (approach/avoidance; intention, redirected and displacement activities; vigilance/startle; warning signals; cognitive biases, apathy and depression-like changes; stereotypic behavior); physiological responses (sympathetic responses; corticosteroid output - often assayed noninvasively via urine, feces or even hair; other aspects of HPA function, e.g. adrenal hypertrophy); and the potential negative effects of prolonged stress on reproduction (e.g. reduced gametogenesis; low libido; elevated still-birth rates; poor maternal care) and health (e.g. poor wound-healing; enhanced disease rates; shortened lifespans). The best validated, most used welfare indices for elephants are corticosteroid outputs and stereotypic behavior. Indices suggested as valid, partially validated, and/or validated but not yet applied within zoos include: measures of preference/avoidance; displacement movements; vocal/postural signals of affective (emotional) state; startle/vigilance; apathy; salivary and urinary epinephrine; female acyclity; infant mortality rates; skin/foot infections;
\end{abstract}

Grant sponsor: NSERC.

*Correspondence to: Georgia J. Mason, Canada Research Chair in Animal Welfare, Animal Science Department, University of Guelph, Guelph, Ontario, Canada N1G 2W1. E-mail: gmason@uoguelph.ca

Received 8 August 2008; Revised 21 April 2009; Accepted 5 May 2009

DOI 10.1002/zoo.20256

Published online 9 June 2009 in Wiley InterScience (www.interscience.wiley.com). 
cardio-vascular disease; and premature adult death. Potentially useful indices that have not yet attracted any validation work in elephants include: operant responding and place preference tests; intention and vacuum movements; fear/ stress pheromone release; cognitive biases; heart rate, pupil dilation and blood pressure; corticosteroid assay from hair, especially tail-hairs (to access endocrine events up to a year ago); adrenal hypertrophy; male infertility; prolactinemia; and immunological changes. Zoo Biol 29:237-255, 2010. (c) 2009 Wiley-Liss, Inc.

Keywords: preference; motivation; cortisol; stress; welfare; zoos

\section{INTRODUCTION}

Ensuring the well being of zoo elephants is challenging in terms of husbandry, cost and public perception. Objectively quantifying elephant welfare also represents a considerable challenge. Here, we review how welfare is assessed scientifically, via behavioral and physiological variables validated and well-used in farm and laboratory animals. We discuss what is known about them for elephants, and consider the work yet needed to improve the objective assessment of elephant welfare. A companion paper [Mason and Veasey, submitted, this volume] reviews the few studies that have used these indices in a way that helps evaluate the populationlevel well being of zoo elephants.

\section{WHAT DO WE MEAN BY WELFARE?}

Welfare relates to an animal's affective (colloquially, "emotional") state: what it feels. Our use of this word is equivalent to the term "well-being" [see e.g. Brown et al., 2008], as we use these inter-changeably in this paper. Good welfare means experiencing positive emotional states, while poor welfare involves severe or prolonged suffering [e.g., Dawkins, 1990; Mason and Mendl, 1993; Brown et al., 2008]. Clarifying what welfare is not helps augment this definition. First, health and welfare are not equivalent; welfare can affect health, as reviewed below and poor health can also affect welfare, if it involves pain or nausea. However, health issues without such effects (e.g., a tumor the animal cannot feel; a latent, quiescent virus; or a potentially painful condition treated effectively with analgesics) do not affect welfare, at least at that time. Second, welfare is not about simple genetic fitness. While poor welfare can decrease reproductive output (as reviewed below), this is not always the case: it would be incorrect, for instance, to assume that all farmed livestock have good welfare simply if reproducing productively. Third, good wellbeing is not about mimicking all aspects of natural life. Performing certain natural activities may be important, but others may be relinquished harmlessly when human provisioning and protection render them obsolete [e.g., Veasey et al., 1996a,b]. Fourth, welfare does not necessarily correspond to the intentions of the animal's human carers: captive animals can have good welfare despite indifferent keepers, or poor welfare despite keepers caring deeply. Finally, death must be differentiated from well-being. How and why death occurs is relevant to welfare, since this may involve suffering (see below). However, loss of life per se does not imply poor welfare: death involves the cessation of brain activity, rendering suffering impossible; death can also be humane (the aim of "euthanasia"). 
If welfare is about how animals feel, then in the absence of a common language, how do we investigate it objectively? Subjective experiences and feelings are inaccessible (the so-called "Other Minds" problem), so to assess them we use indirect indicators. When evaluating welfare in other humans, we use both learned language and innate signals (smiling, crying, etc.), whose affective correlates we understand from our own experiences. These indices generally serve us well. However, they can be challenging or unreliable in nonverbal humans like babies or the profoundly disabled: such cases may require measuring heart-rate or other physiological changes validated (as discussed below) as indices of affect. When evaluating well-being in other species, even greater challenges occur: reading alien signals (ear-flapping, growling, etc.); assessing physiological changes without inducing handling/sampling stress; distinguishing valence (the positive/negative nature of emotions, central to well-being) from mere arousal (alertness and activity, which can increase in positive as well as negative situations); and last but not least, interpreting all findings without anthropomorphism, bias or circular reasoning. Certainty about conscious experiences in other animals is thus impossible; and socalled "welfare measures" are merely indices from which we make only inferences.

But what are these indices and where do they originate? Most come from two well-established fields:

1. Clinical research in humans with physical or mental problems: Verbal reports from suffering people (enduring stressful events like war, divorce, or bereavement; suffering from emotional disorders such as anxiety and depression; or experiencing physical harm that causes pain or nausea) are compared with changes in biological functioning (e.g., cognitive changes, hormonal profiles, or immunological changes), to yield potential biological correlates of affective state.

2. Animal-based physiology and neuroscience research: To investigate human clinical conditions (e.g. anxiety and depression), laboratory animals are deliberately exposed to events believed to cause stress, fear, sickness, or pain, and/or have such suffering experimentally mitigated via analgesic or anxiolytic drugs. Behavioral and physiological changes again yield candidate indices of the affective states induced/redressed by these treatments.

Both these fields tend to yield similar indices, providing a range of potential tools, as reviewed next, for assessing animal well-being.

\section{HOW TO ASSESS ELEPHANT WELFARE?}

Here, we summarize key welfare indices, especially those sensitive to psychological well-being (stress, frustration, and anxiety/fear), as detailed in many stress and welfare texts [e.g., Archer, 1979; Dawkins, 1980, 1990; Mason and Mendl, 1993; Broom and Johnson, 1993; Toates, 1997; Clubb and Mason, 2002, p. 7; Brown et al., 2008; further references are given below where they refer to additional specifics]. We cover behavioral and psychological changes (A), then physiological changes (B), and, finally, the consequences of physiological changes for reproduction and health (C). We also review species-specific research on these indices in elephants. Our aim is to evaluate the usefulness of various indices for assessing zoo elephant 
welfare, recommend how best to use them in practice, and highlight potentially valuable indices that have been overlooked.

\section{Behavioral and Psychological Changes}

Behavioral changes and the underlying CNS processes (e.g., appraisal, decision-making, and learning) are central to welfare assessment because often inherently related to pleasure, fear, and other feelings.

\section{Preference and avoidance}

Stimuli or events that decrease welfare are typically avoided, while stimuli or events that increase welfare are typically sought out. This can occur via unlearned responses (e.g., approach), or learned ones such as performing an arbitrary operant task (e.g., lever-pressing) or moving to specific locations associated with reward ("conditioned place preference"). The more important a resource, the more effort is generally devoted to gaining it: thus animals typically work harder (travel farther, overcome greater obstacles, lever-press faster, etc.) for food and water than for nonessential resources, especially when deprived. Such behavioral responses are intimately related to the value of different stimuli and experiences: many argue that the very functions of emotions are to control motivation (goal-directed, effortful aspects of behavior) and promote learning [e.g., reviewed by Dawkins, 1990]. Preference tests have thus often been used to reveal what animals choose for improved well-being. For example, chickens prefer larger cages with a substrate to smaller cages with wire floors [Dawkins, 1983], while naturally semi-aquatic American mink will push door-weights as heavy as those they will push to gain food, to reach water in which they can swim and "head-dip" [Mason et al., 2001]. Negative stimuli can be evaluated too; for example, the avoidance of potentially noxious gasses can be assessed [Cooper et al., 1998; Jones et al., 2003], while the aversiveness of pain to lame poultry has been revealed by their selection of food dosed with analgesics over unadulterated food [e.g., Danbury et al., 2000]. Thus, investigating whether stimuli or experiences induce learning, and quantifying the efforts animals make to reach or avoid them, can be very useful for identifying and ranking their affective valence.

Issues to be aware of when applying such techniques include animals requiring time to experience and learn about the positive or negative effects of the stimuli on offer. In addition, preference data may need interpretation: threatening stimuli can occasionally elicit approach because of the need to gain information about potential danger (e.g., "predator inspection" by prey species); and, furthermore, when animals interact with a rewarding resource, the stimuli elicited by it (its sounds, odors, etc.) and experience gained by interacting with it, may enhance or even create a motivation for it - without such effects, "out of sight" could well have been "out of mind." Thus, preference for environmental enrichments, say, reveals the benefits of adding them to an enclosure and the welfare implications of removing them once they have been enjoyed, but does not prove that animals that have never experienced such enrichments are suffering [Warburton and Mason, 2003].

Preference and avoidance measures are likely very useful for elephant welfare assessment. Studies of wild African elephants' ranging behavior certainly reveal clustering around important resources like water [Chamaillé-Jammes et al., 2008], and the avoidance of potential threats or wastes of energy. Thus, they show 
avoidance of roads [e.g. Blake et al., 2008] and of other areas or signs of human disturbance [Slotow, 2002; Blom et al., 2004]; they avoid walking uphill [Wall et al., 2006; Edkins et al., 2008; see Limin and Li, 2005 for similar findings for Asian elephants]; and they flee from the sounds of enraged bees [King et al., 2007], from hunts [Burke et al., 2008], and even from the odors of ethnic groups, Masai, who sometimes kill them [Bates et al., 2007; the sight of distinctive red Masai clothing, in contrast, elicits approach and attack]. In zoos, however, studies of preference or avoidance have been little used as yet [Mellor et al., 2007 give one preliminary example], but they could potentially be very valuable. For example, place preference paradigms could be used to investigate whether elephants dislike being shackled at night, whether they find some keeper contact rewarding (perhaps even the odors/ clothes of keepers with different handling styles could be presented), and to address many other topical welfare issues. In addition, operant approaches could be used to evaluate potential positive and negative experiences and their importance to zoo elephants. If slopes are avoided, perhaps ramps of varying steepness could also be used as experimentally imposed nonoperant costs, to assess efforts elephants are prepared to make to reach/avoid different resources or stimuli [Schulte et al., 2007 review some other non-operant barriers or obstacles that could potentially allow evaluation of motivations to approach/retreat].

\section{Other behavioral measures related to preference, avoidance and other motivations}

Tendencies to avoid threatening stimuli can be used in a quite different way in welfare assessment. For one, avoidance responses (e.g., "startle") can be valuable for assessing state, not just for quantifying the aversiveness of particular stimuli, since increased tendencies to avoid novel, standardized threats reflect increased underlying anxiety. These we review in detail in the following section. (Decreasing tendencies to avoid familiar, repeated stressors may in contrast indicate "learned helplessness:" see "Apathy and depression-like changes," below.) In addition, frustrated motivations (e.g. thwarted desires to approach or avoid stimuli or to engage in other activities) can cause other behavioral responses useful in welfare assessment: "intention movements," where animals attempt to reach a relevant resource despite repeated failure; "redirected" and "vacuum" activities, where inappropriate stimuli are used as outlets for motivation (e.g., mating with inanimate objects); and "displacement activities," where a conflict between two incompatible motivations induces irrelevant activities like grooming. These responses can thus help reveal an animal's affective state. Furthermore, if repeated and sustained, these movements can potentially give rise to stereotypic behaviors - abnormal behaviors reviewed in more detail below.

Free-living African elephants certainly seem to display distinctive displacement activities [reviewed and illustrated in Poole and Granli, 2009]. In an ambivalent, slightly apprehensive animal, apparently unsure of what action to take, these include trunk-twisting (the trunk-tip being twisted back and forth), foot-swinging (raising and tentatively intermittently swinging the foreleg, or occasionally the hind leg), and "touch face" (touching the trunk to the animal's own face, mouth, tusk, or temporal gland). Displacement grooming and displacement feeding also occur, activities characterized by situational and functional inappropriateness. For instance, caught between two incompatible motivations (e.g. fleeing and fighting), wild African 
elephants may begin to throw dust or grass onto themselves, or pluck at vegetation without ingesting it. Such indices seem not, however, to have been used in studies of captive elephant well-being.

\section{"Startle" and other responses to potentially threatening stimuli}

Many tests of fear, especially those conducted on rodents to investigate anxiety, involve assessing reactions to a standardized "probe" stimulus that is inherently mildly aversive [e.g., Crawley, 2007]. Such stimuli include open, brightly lit areas or novel objects, which rodents typically avoid. Importantly, such avoidance responses increase in individuals previously exposed to treatments that increase anxiety (e.g., social isolation; predator odors), but decrease after anxiolytic drugs. Another innate avoidance response used to assess anxiety is the "startle" induced by a sudden, standardized sound or touch; again, animals previously exposed to stressors show more exaggerated startle responses than control animals, while anxiolytic drugs reduce these responses. These anxiety indices are standard in biomedical research using rodents; have recently been applied to rodent welfare research; and have just started to be used elsewhere, for example, with farmed ungulates. On the contrary, their application in zoos has been negligible, with no known usage in elephants as yet, neither to assess what stimuli cause fear, nor-via the use of probe stimuli-to assess background anxiety.

Signs of increased vigilance such as "head-up" scanning postures or eye widening [which probably functions to increase peripheral vision; Susskind et al., 2008] may also be useful welfare indicators. For example, eye-widening that shows the whites is a well-validated fear/distress index in cattle [e.g., Sandem et al., 2002; Core et al., 2009], again to both identify negative stimuli and, by using standardized "probe" stimuli, assess underlying anxiety. Eye-widening revealing the whites similarly occurs in wild African elephants when alarmed or anxious [Poole and Granli, 2009]. However, it is also seen during intense social interactions and excited play [Poole and Granli, 2009]. This suggests that while eye-widening could be useful in elephant welfare assessment, one must control high levels of general arousal since this is a potential confound (an issue returned to below). Other behavioral signs of alarm/vigilance in wild African elephants include freezing, scanning, and smelling the air [O'Connell-Rodwell et al., 2007].

\section{Signals to conspecifics}

Group-living animals and mothers and infants often signal to each other about emotionally significant events, particularly danger but also sometimes seemingly to convey relaxation (e.g., cats purring). Such signals are typically species-specific, and can be visual, auditory, or olfactory. Examples used in welfare assessment include vocal pain responses in piglets [Weary et al., 1998] and chromodacryorrhoea, a stress-related red tear-like secretion, in rats [Mason et al., 2004]. Caveats when using animal signals in welfare assessment include the risks of anthropomorphism faced with signals that look like our own (e.g., liquid running from the eyes), and conversely our insensitivity to other animal signals (such as sounds at frequencies our ears cannot detect, and odors). Another caveat is that signals are typically problem-specific (e.g. signaling-specific states like hunger or fear, but not "general poor welfare"). 
Wild elephants display many signals that seem affectively significant, including diverse trunk and ear postures [e.g. Poole and Granli, 2009]; for example "head low" and "ears-back" postures occur during appeasement, while "trunk curled under" occurs during apparent alarm/apprehension. Liquid "temporin" flow from the temporal glands has also anecdotally been linked with excitement and high arousal, including stressful situations. Slotow [2002] even suggests that temporin flows when wild elephants are disturbed by humans, though not all agree, most interpreting it as a socio-sexual signal [e.g., Weibull and Eriksson, 1998; Sukumar, 2003].

These postural, vocal, and other signals are doubtless used in an informal, everyday way by perceptive elephant keepers. However, their validation for and formalized application to elephant welfare assessment seems undeveloped. One potential exception is a recent acoustic analysis of zoo animals' rumble vocalizations, made during apparently positive and negative social interactions [Soltis et al., 2009]. These differed measurably, particularly in energy content. This study could not disentangle valence from mere arousal, but nevertheless if developed, this type of research could yield validated indices of affect for future use.

Note that not all signals of warning, fear, or distress made by elephants are readily detected by humans. For example, some alarm calls of African elephants are infrasonic [Moussaieff Masson and McCarthy, 1995; O'Connell et al., 2007], and so hard to monitor without specialized equipment. Olfactory signals are also hard to assay [though the effect of, say, urine from stressed or unstressed animals on conspecific behavior can be used as a "bioassay:" see Mason et al., 2009].

\section{Cognitive biases}

Humans in negative moods (e.g. sad or scared), or with clinical depression (see below), show pessimistic skews in how they perceive and classify events: in particular, neutral or mildly negative events are judged as being more negative or threatening than they are by people in positive moods. Similar "cognitive biases" occur in animals [e.g. Harding et al., 2004; Burman et al., 2008; Matheson et al., 2008]. Thus in one study [Harding et al., 2004] rats were trained that if they heard a sound at a certain pitch, food would be delivered if they pressed a lever, while if they heard a sound of another pitch, the lever would instead emit a blast of aversive noise. These trained rats were then housed in two ways: in large enriched cages or in standard cages made stressful by regular disruption. The two groups were re-exposed to the two sounds, but also to a range of probe sounds of intermediate pitch. Enriched rats treated these ambiguous sounds "optimistically," as though predicting a lever-delivered treat, but stressed rats treated them "pessimistically," as if signaling that lever-pressing would be punishing [see also Burman et al., 2008; Matheson et al., 2008].

Quantifying cognitive bias is valuable because subject to minimal confounds (e.g. not influenced by arousal/activity, like many other indices of affect); because negative biases potentially cause as well as reveal welfare problems; and because positive bias is a rare example of an index of good well-being. Cognitive bias has not yet been used to assess zoo animal well-being, but could be ideal, especially for elephants whose learning abilities should facilitate training in the relevant tasks. Such approaches might address whether new arrivals to a herd have negative cognitive biases compared with more settled members; whether removing a mother's 


\section{Mason and Veasey}

calf leads to negative cognitive bias; whether large enriched enclosures induce positive cognitive biases; and many other relevant welfare questions.

\section{Abnormalities in behavior and brain function I: Apathy and depression-like changes}

As well as negative cognitive biases, humans with depression show reductions in activities that require motivation or usually cause pleasure, e.g., personal care, work, exercise, social interaction, and sexual activity. Similarly, low levels of activity and reduced libido are often observed in rodents subject to repeated stressors (indeed stressors are applied to rodents in order to "model" human depression in biomedical research). Low levels of activity, poor self-grooming, low libido, and a lack of interest in maternal care are likewise often observed in captive animals, and are sometimes labeled "apathy." However, typically, it is hard to confidently classify these changes as truly depression-like; validation would include evidence of concomitant changes in cognitive bias (see above) or endocrine function (especially in the HPA axis: see below), and the reversal of these effects with antidepressants. In laboratory animals experimentally exposed to repeated stressors that they cannot escape from (e.g. unavoidable electric shock), a paradoxical lack of avoidance of the harmful stimuli can occur too. Termed "learned helplessness," this passivity is also held to mimic aspects of human depression. However, in zoo animals showing superficially similar effects, it would be hard to tell an individual that has successfully habituated (so no longer finding the stimuli aversive), from one with true "learned helplessness:" further validatory data (e.g. the cognitive, endocrine, and pharmacological approaches listed above) would be required.

Thus overall, when captive animals are labeled "apathetic" or "depressed," the term is potentially valid - but in practice applied very subjectively. This caution noted, there have been striking, if anecdotal, accounts of elephants becoming very quiet and inactive after social separation [Moussaieff Masson and McCarthy, 1996] or "trauma" [Derby, 2008]. Ill elephants are also said to move their trunks, switch their tails and flap their ears less than healthy animals [Chatkupt and Sollod, 1999, citing Schmidt, 1986]. Furthermore, in a survey of Thai working elephants [Chatkupt and Sollod, 1999], elephants that moved "intermittently" were found to have poorer body condition than those that moved "frequently," as were those described as "dull" or "quiet." While such categorization was subjective and confounds abounded (for instance poor body condition and little movement were both seen in animals with insufficient shade), attempts to validate and utilize such behavioral indices could well prove valuable in future welfare studies.

\section{Abnormalities in behavior and brain function II: Stereotypic behavior}

Abnormal repetitive behavior, such as stereotypic pacing, is common in zoos [e.g., Mason et al., 2007]. It has long been used in welfare assessment for two reasons: it often originates from intention movements and other behavioral signs of frustrated motivation (see above); and meta-analyses show that it is most evident in treatments or environments that induce other signs of poor well-being [Mason and Latham, 2004; Mason et al., 2007]. Indeed, stereotypic behaviors have recently been formally defined as "repetitive behaviors induced by frustration, repeated attempts to cope, and/or central nervous system (brain) dysfunction" [Mason, 2006]. This distinguishes them from repetitive behaviors that do not indicate poor welfare (e.g., a cat kneading a comfortable lap, or a dog circling before settling to sleep). Two key 
caveats when using abnormal repetitive behaviors to infer well-being are as follows. First, they may indicate past problems more than current ones [for instance, if they reflect abnormal brain development during infancy; Mason, 1991; Mason and Latham, 2004; Mason et al., 2007]. Second, whether groups or individuals with negligible stereotypic behavior truly have better welfare than those with high levels depends on what they are doing instead: if they are "apathetic" (see above), hiding, or immobile due to pain [e.g., Mellor et al., 2007], their welfare may actually be poorer than that of animals with overt abnormal behavior. Thus empirically, within populations showing abnormal repetitive behavior, those individuals with the highest levels often seem to cope best (as assessed via other welfare indices) with the sub-optimal environments in which they live [Mason and Latham, 2004].

Typical abnormal repetitive behaviors in zoo elephants are swaying/weaving, head-nodding, and sometimes pacing; the trunk may be moved in a repetitive and unvarying way too [reviewed by Clubb and Mason, 2002; Harris et al., 2008]. In a recent survey of all UK zoos, side-to-side swaying/weaving was indeed the most common across this population, while the rarest form involved repeatedly rubbing tusks on bars and ropes, wearing grooves into the ivory [Harris et al., 2008]. Are these repetitive behaviors stereotypic? At least some are increased by treatments like tethering [e.g., Friend, 1999; Kurt and Geraï, 2001], or stressors like the onset of parturition [Szdzuy et al., 2006] or approach of a dominant conspecific [Derby, 2008], and so it seems reasonable to class these responses in elephants as true stereotypic behaviors. However, in a few cases they may reflect past problems more than present; for example, zoo elephants originating from circuses are particularly prone to this behavior [Harris et al., 2008]. This issue acknowledged, several studies have used stereotypic behavior to investigate zoo elephant welfare, including in animals who have lived in zoos all their lives.

\section{Physiological Responses and Their Effects}

Behavioral and psychological responses to threats or stressors are supported (e.g., fuelled) by appropriate changes in underlying physiology. These necessary, adaptive changes underlie such "stress responses" as racing hearts, dilated pupils, and so on. These are potentially useful to assess short-term changes in well-being; furthermore, if activation is prolonged or excessive, harmful side effects can also occur (reviewed in the following section).

\section{Adrenaline (epinephrine) release and other sympathetic responses}

The release of the catecholamines adrenaline (epinephrine) and noradrenaline (norepinephrine) into the bloodstream from the adrenal medulla is part of the sympathetic response - a suite of neural and hormonal changes that help optimize the performance of behaviors needing energy, such as fleeing or fighting. Effects include increased catabolism, increased heart and respiration rates, increased blood pressure, and pupil dilation. Catecholamines are secreted during an animal's normal activity periods, thus typically displaying a circadian pattern in most species, but are also elevated by aversive stimuli. Note that parasympathetic activation, sometimes treated simplistically as an index of calmness, can also play a role in this acute autonomic stress response, prompting urination and defecation. 


\section{Mason and Veasey}

All these are common correlates of acute stress or fear; and in humans with chronic anxiety, such responses may be elevated for long periods of time. In animal studies of fear and anxiety, especially rodent-based research, defecation rates are often recorded, while heart rates may be assessed via surgically implanted devices or strap-on external heart-rate monitors (the latter used successfully in welfare research on large domestic ungulates). Furthermore, adrenaline and noradrenaline can be detected in saliva and urine: noninvasive techniques of inferring plasma levels that minimize risks of the sampling itself elevating the hormones being measured. The main caveat when using such indices in welfare assessment is that they are also sensitive to activity and arousal in general, and so can also increase during pleasurable behavioral activities, such as playing or copulation. Heart-rate and blood pressure are also affected by posture (often increasing with lateral recumbency in large mammals); furthermore, catecholamines are labile and so for valid assay need rapid deep freezing after collection.

In terms of using the sympathetic responses of elephants in welfare assessment, adrenaline and noradrenaline levels can be assayed from urine [Dehnhard, 2007], and adrenaline can also be extracted and assayed from elephant saliva [Exner and Zanella, 1999]. Dehnhard [2007] successfully showed that urinary catecholamines were elevated in two cows after being transferred, a presumably acutely stressful event. Soltis et al. [2009] also used urination/defecation by subordinates during a social encounter as evidence of negative affective, although this index seems not to have been formally validated. Heart rates, which typically range between 24 and $50 \mathrm{bpm}$, can be measured by means of external electrodes [Bartlett, 2006], but seem not to have been recorded as part of any welfare-oriented study as yet; the same appears true for blood pressure.

\section{The hypothalamic-pituitary adrenal axis I: Corticosteroid levels}

For physiologists, the hypothalamic-pituitary adrenal (HPA) axis is the classic stress system of the body [see Brown et al., 2008 for a good review]. Glucocorticoids are secreted by the cortex of the adrenal gland, in response to the release of adrenocorticotrophic hormone (ACTH) by the brain's pituitary. The functions of these hormones includes facilitating the mobilization of energy reserves to prepare the animal for a response such as fight or flight. Thus, like catecholamines, they show a circadian pattern that relates to normal activity cycles, but are also elevated by threat. They complement sympathetic responses, but typically are activated for longer after a threat and have more diverse secondary effects on other physiological processes throughout the body.

Assessment of HPA activity in animal welfare work typically involves measuring ACTH and corticosteroids in the plasma; corticosteroids diffusing into the urine or saliva (as with adrenaline, concentrations in these fluids track those in the plasma, while being easier to sample without stress); or corticosteroid metabolites evident in the feces. Whether urine or feces is the main route for excreting these hormones varies between species and even sexes [e.g., Touma et al., 2003 on mice]. Techniques have also been developed recently to assay corticosteroids laid down in follicles during hair/fur growth. Assaying hair steroids to infer the timeline of significant past events has long been used in human drug-testing, thanks to the serial, stable deposition of such compounds along the hair shaft [see Davenport et al., 2006]. Recently, endogenous corticosteroid deposits have similarly been 
assayed in hairs from macaques, cats, and dogs [Davenport et al., 2006; Accorsi et al., 2008]. Like sympathetic responses, HPA responses sometimes have to be treated with caution in welfare research because acute elevations in glucocorticoids can occur during excitement or simple exertion, not just in situations where wellbeing is compromised. Corticosteroid outputs also vary with estrus status in elephants [Oliveira et al., 2008]. A final confound is that, as reviewed in the next section, levels can sometimes fall with severe or early life stress.

In elephants, cortisol is the key corticosteroid produced by the adrenal [e.g., Brown et al., 2008]. Baseline levels, or rapid, brief elevations of cortisol output, may be detected in both elephant saliva [Dathe et al., 1992; Exner and Zanella, 1999; Menargues et al., 2008] and urine [Brown et al., 1995]. Baseline levels and longer, more sustained changes in output may also be detected via metabolites in the feces [Stead et al., 2000; Wasser et al., 2000; Foley et al., 2001; Ganswindt et al., 2003; Millspaugh, 2003; and Hunt and Wasser, 2003 for Africans; e.g., Laws et al., 2007 for Asians]. These metabolites peak in the feces approximately $30 \mathrm{hr}$ after a stressful event. It does not yet seem clear whether urine or feces is the main route for cortisol metabolite excretion in elephants, nor whether this varies between sexes. Biological validation of fecal assay techniques in wild elephants includes the increase of cortisol metabolites with natural stressors like being a subordinate herd member, being exposed to severe dry seasons, experiencing a thunder storm, or being injured [Wasser et al., 2000; Foley et al., 2001; Ganswindt et al., 2005; Millspaugh et al., 2007], and with anthropogenic stressors like being hunted [Burke et al., 2008] or translocated [e.g., Viljoen et al., 2008]. Fecal cortisol metabolite levels also co-varied with submissive behavior in one study of zoo elephants [Burks et al., 2004].

A final assay technique with untapped but enormous potential for elephants is to quantify cortisol trapped in hair. Research in a quite different field has shown that certain isotopes deposited in free-ranging wild elephants' tail hairs reliably reflect their movements and diets over the previous 12 months [Cerling et al., 2006]. Thus, if cortisol extraction techniques were validated for elephant hair, the long strands from their tails could potentially be used to assess the impact of events throughout the previous year, which could be extremely useful for the retrospective investigation of past experiences (e.g. moves from zoos to sanctuaries, weaning, past changes in herd composition, etc.).

\section{The HPA axis II: Changes in HPA functioning}

In cases of chronic stress, HPA outputs and responsiveness can be chronically elevated; this can even result in the hypertrophy of the adrenal gland cortex [e.g., Terio et al., 2004]. The HPA system can also respond with changes in circadian patterning (the loss of the normal night-time trough occurs in some humans with depression), or even with decreased adrenal activity largely due to upregulation of negative feedback loops within the axis and/or habituation of the adrenal to ACTH [see also Brown et al., 2008]. Thus, while chronic elevation is a likely sign of severe welfare problems, unchanged or even reduced activity may also occur, making interpretation complex and in need of validation by other measures, particularly ACTH levels, signs that any chronic changes in HPA function have caused lasting harm (see below), and independent welfare indices. 


\section{Mason and Veasey}

Long-term studies of HPA output or changes in circadian patterning seem not to have been conducted on zoo elephants; there also seems to have been no use of adrenal size/structure post mortem to assess the merits or demerits of particular husbandry systems, even though elephant adrenals have been well-studied [Kramer et al., 1991] and are typically removed during necropsies (cf. AZA standard protocols).

\section{Negative Effects of Prolonged Physiological Stress}

If stress is chronic, health and fecundity may be affected, partly due to direct effects of over-activation of the endocrine systems involved (e.g., on reproductive physiology and inflammatory pathways), and partly due to resulting reduced immune responses to pathogens. Thus, consequences of chronic physiological stress include immunosuppression (possibly combined with pro-inflammatory states), poor wound healing, reduced fertility, reduced protein synthesis (e.g., body-mass loss), chronically elevated blood pressure, gastric ulceration, increased parasite loads, elevated pathogenicity of opportunistic infections, and even premature death.

\section{Reduced reproductive success}

A well-documented effect of chronic stress in humans, research rodents, and many other species [see reviews by e.g., Wingfield and Sapolsky 2003; von Borell et al., 2007; Clubb et al., 2009] is reduced fertility. In adult females, this can be manifest as impaired cycling/reduced estrous periods, low libido, premature reproductive senescence, reduced conception rates, increased pre-term fetal losses, prolonged parturitions, smaller birth weights, asymmetrical infant development, increased offspring stress responsiveness, poor maternal care (or infanticide), and/or increased infant mortality. Many of these effects stem directly from HPA axis overactivation, but additional causal factors include stress-induced prolactin elevation [Sobrinho, 1998, 2003] and, more speculatively, luteolytic stress-activated protein kinases [as activated by mitogens: Yadav et al., 2001]. Oxytocin, too, is a crucial reproductive and maternal hormone, especially during parturition and in the early stages of maternal care, whose release can be inhibited by stress [see e.g., Leng et al., 1987; Pedersen and Boccia, 2002; Kiecolt-Glaser et al., 2002].

Just as for most welfare indices, reduced fecundity is far from a perfect index that always indicates negative affect. Factors reducing reproductive rate that are independent of well-being include obesity and lack of adequate socialization with opposite sex conspecifics when young. Several such explanations apply specifically to elephants. For example, Hermes et al. [2004] suggest that the mere lack of breeding when young accelerates reproductive senescence in these species - although in zoos, such data are correlational only (not causal), and so do not preclude the possibility that females that fail to breed when young had subclinical problems even then, only manifest overtly later in life. Other impediments to elephant reproduction that are unlikely to reflect poor psychological well-being include: hypocalcaemia [van der Kolk et al., 2008; Hermes et al., 2008]; poor physical fitness compromising parturition [Hermes et al., 2008]; dam parity and past experience (including with the infants of other females); and, critically, restricted access of females to males and limited mate choice (due to the way cows and bulls are largely kept separate). 
Overall, however, these caveats acknowledged, chronic stress remains a sensible hypothesis to explore, especially when there is evidence of diminished fecundity not caused by mere single sex groupings. However, thus far there has been rather little work on the impact of stress on elephant reproduction in captivity. Wildcaught Asian timber elephants, who experience very stressful "breaking" processes followed by high mortality rates, have lower fecundity than captive-bred animals working in the same conditions [Mar, 2007]. Furthermore, in wild African elephants, females from herds socially disrupted by poaching, show low calf outputs, despite being in their reproductive prime [Gobush et al., 2008]. However, despite the research reviewed above on the assessment of HPA activity, and despite preliminary work to develop assays for stress-activated proteins in African elephants [Bechert and Southern, 2002], only one laboratory, Janine Brown's, has investigated possible links between stress and reproductive success in zoo elephants. So far, Brown's work has focused on acyclicity only; it has revealed no significant links between this and HPA output (although the highest cortisol levels did seem to occur in noncyclers), but in Africans, acyclicity was linked with elevated prolactin levels that stemmed from super-normal prolactinemia in about one-third of the noncycling population [Brown et al., 2004]. As yet, there seem to have been no studies of the possible role of stress (perhaps acting via prolactin or oxytocin) in the long parturitions, high infant mortality rates, and other reproductive problems common in zoo elephants. (See also Mason and Veasey, submitted to this volume, for more detail.)

\section{Increased morbidity and decreased lifespan}

In humans, stress causes increased susceptibility to both opportunistic infections (e.g., oral and gastric ulcers, fungal infections, skin boils, and Herpes sores) as well as to infectious diseases caught from conspecifics (e.g., colds and influenza) [e.g. Kiecolt-Glaser et al., 2002, 2003; Danese et al., 2007]. It also impairs wound healing, and increases the severity and prevalence of noninfectious pathologies (e.g. cancer and cardio-vascular disease). Similar effects can be seen in a range of other species [cf. Mikota, 2008; Clubb et al., 2009]. Chronic stress therefore decreases life expectancy, in species as diverse as rats, humans, and rhesus monkeys [reviewed by Clubb et al., 2009], the typical pattern being is that stress shortens mature adult lifespan [e.g., Kiecolt-Glaser et al., 2002; Cavigelli et al., 2005; see also Mason and Veasey, submitted to this volume, for more detail].

These potential consequences of chronic stress can thus be useful in assessing animal welfare, not least because they may cause as well as reflect poor welfare. Potential confounds, however, when using morbidity and mortality data to make inferences about well-being, include that infection rates/severities do not just reflect factors intrinsic or endogenous to the individual, but also extrinsic factors too, such as exposure rates to pathogens and the quality of veterinary care available. Furthermore, many noninfectious diseases can be affected by diet and exercise as well as stress; thus lifespan, for instance, can be reduced by a host of other variables, some of which, like access to ad lib. food and thence excess body fat, may even be positive for psychological welfare. Mortality rates must thus be viewed as good barometers of husbandry, but not necessarily of welfare per se. Despite these issues, if used carefully, data relating to mortality may be useful in zoo welfare assessment because zoo animals are frequently allowed to reach maximal longevity. Disease rates could too, if co-occurring with other signs of poor well-being. 


\section{Mason and Veasey}

In elephants, does stress affect health and longevity? Sikes [1968] reported that wild African elephants can succumb to cardio-vascular disease. He also argued that this was caused by stressful over-crowding and habitat degradation, though not all agree with this interpretation and other measures of stress were not taken from these animals. In Asian elephants taken from the wild to work in timber camps, stressful capture and "breaking" is followed by a period of dramatically elevated risk of death that last for several years [Mar, 2007; Clubb et al., 2008], although the biological causes of these deaths are unknown. Foley et al. [2001] found a correlation between corticosteroid levels and conspicuous signs of gastro-intestinal parasites in wild African elephants. This would be consistent with a link between stress and increased vulnerability to parasitism, although equally could indicate an increase in stress as a result of infestation. Finally, in a recent survey of $16 \mathrm{UK}$ zoo elephants, lameness scores co-varied with fecal corticosteroid metabolite outputs, the lamest animals showing greatest endocrine signs of stress [Rajapaksha et al., 2006]. Again, this could be consistent with stress contributing to the etiology of some foot problems, but it could equally just reflect that pain and disability cause stress (furthermore, this result does not appear to be reported in Harris et al., 2008's larger study of this population). Overall, morbidity and mortality - and potential risk factors like elevated blood pressure, thymus involution, and poor wound healing - thus could be affected by stress levels in elephants, just as in other species, but there has been little in-depth research.

\section{DISCUSSION: AN OVERVIEW OF POTENTIAL WELFARE INDICES FOR ZOO ELEPHANTS}

As we review, several behavioral, physiological, and health-related variables are used in scientific animal welfare assessment. The best animal welfare research controls for known potential confounds (e.g. activity levels, time of day, or stage of estrus cycle); uses indices that are well-validated, and whose strengths and weaknesses are well-understood; tests clear hypotheses, selecting measures best suited for the specific questions under study; and typically uses multiple approaches, because, as we have seen, no one single welfare index is perfect. It is worth noting that poor quality welfare research, in contrast, fails to control for or acknowledge confounds or alternative explanations for findings; uses poorly chosen or validated measures, to test unclear hypotheses (an approach potentially fraught with circular reasoning); and often relies on just a single measure.

To date, the most thorough scientific welfare research has been done on farm and laboratory animals. Farm animal welfare assessment has been a research topic for over 30 years. Laboratory welfare research, although not as venerable, benefits from the use of laboratory animals as models to study anxiety and depression, such that well-validated indices of these states abound for these species. Work on zoo animals, including elephants, lags far behind. However, there has been good work on some species [e.g., clouded leopards and black rhinos; see Carlstead et al., 1999; Wielebnowski et al., 2002]. Furthermore, several potential welfare indices have been well-validated for elephants, in the sense that reliable measurement techniques have been worked out, the indices have been shown to change in situations generally agreed a priori to cause stress or other forms of reduced well-being, confounds are fairly well-understood, and sometimes they have also been shown to co-vary with 
other potential welfare indices. This is a cause for optimism. There is thus real scope for welfare indices to be used in zoos to both monitor and improve the welfare of specific, known elephants, as well as to follow the farm and laboratory animal model in collecting data from larger sample sizes to make recommendations that apply broadly across the population. Some uses of these indices to assess the welfare of zoo elephants in general are reviewed elsewhere by Mason and Veasey [submitted].

As we also show here, however, many other potentially valuable indices for elephants still await proper validation - or even any investigation at all. Elephant welfare indices that have been suggested as valid, partially validated, or validated but not yet applied in any meaningful way in zoos, include: measures of preference/ aversion; intention, vacuum and displacement movements; vocal/postural signals; startle/vigilance; apathy; salivary and urinary epinephrine; female acyclity; infant mortality rates; skin/foot infections; cardio-vascular disease; and premature adult death. Furthermore, many indices have not yet attracted any study at all in elephants-despite their great potential value. These include: operant responding and place preference tests; fear/stress pheromone release; cognitive biases; heart rate, pupil dilation and elevated blood pressure; corticosteroid assay from hair (potentially very useful for the retrospective assessment of events months past); adrenal hypertrophy; male infertility, prolactinemia; and immunological changes.

Does this lack of research matter? After all, for many, scientific approaches to captive elephant welfare issues will seem painfully pedantic and unnecessary ("Isn't it obvious that small concrete enclosures are bad?"). We argue that the use of scientific welfare indices has major advantages over just assuming that we "know" what elephants need for good well-being. First, where there are assumptions about what elephants need for good welfare based on human perspectives (e.g., "they have little to do, therefore boredom must be a source of misery"), such indices can be used to test these assumptions objectively. Second, when contrasting opinions exist about the potential causes of and solutions to welfare problems (e.g., hypotheses about whether human contact substitutes for interactions with conspecifics, or whether environmental complexity is an adequate substitute for space), such data could reveal objectively which viewpoint is correct. Third, where welfare needs are costly to meet, or in practical terms mutually exclusive (cf. e.g., having large social groups versus lots of space per animal), such data can help rank which are most important to provide. Overall, if elephant husbandry is to be evidence-based, and elephants' own perspectives (rather than human assumptions) are to guide how they are housed and cared for, then welfare indices like the ones described here need to be validated, refined, and above all, used. In the following paper [Mason and Veasey, submitted], we survey what the few such studies to date suggest about zoo elephant well-being at the population level.

\section{CONCLUSIONS}

1. Animal welfare is about feelings - states like "suffering" or "contentment," which we cannot measure directly, but can infer from certain behavioral and cognitive responses, physiological responses, and effects on reproduction and health.

2. All these indices have their pros and cons, and good quality animal welfare research therefore typically uses multiple, complementary, well-chosen indices to reduce the risks of confounds. 
3. Currently, there are just two well-validated, commonly used welfare indices for elephants: corticosteroid outputs (often assayed from feces) and stereotypic behavior. Both have their limitations.

4. Several other indices have been suggested as valid, partially validated, or validated for elephants but not yet applied in zoos (for example, measures of preference/aversion; startle/vigilance responses; salivary and urinary epinephrine; cardio-vascular disease; some infections), while several further potential welfare indices have not yet attracted any study at all in elephants (e.g. fear/stress pheromone release; heart rate and pupil dilation; corticosteroid assay from hair; adrenal hypertrophy; prolactinemia; immunological changes).

5. We argue that objective welfare indices for elephants need to be better developed, since they should play a central role in evidence-based elephant management.

\section{ACKNOWLEDGMENTS}

Many thanks go to Debra Forthman for her encouragement, patience, and help with an earlier version of this work; to Janine Brown and two anonymous referees; to Phyllis Lee for discussions on Sikes' work in Tsavo; and to Joyce Poole for access to her unpublished book chapter on elephant signals. Georgia Mason is funded by NSERC.

\section{REFERENCES}

Accorsi PA, Carloni E, Valsecchi P, Viggiani R, Gamberoni M, Tamanini C, Seren E. 2008. Cortisol determination in hair and faeces from domestic cats and dogs. Gen Comp Endocrinol 155:398-402.

Archer J. 1979. Animals under stress. Studies in biology 108. London, UK: Edward Arnold.

Bartlett S. 2006. Cardiovascular system. In: Murray E, Fowler ME, Mikota SK, editors. Biology, medicine, and surgery of elephants. Oxford, UK: Blackwell-Wiley. p 317-324.

Bates LA, Katito N, Sayialel KN, Njiraini NW, Moss CJ. 2007. Elephants classify human ethnic groups by odor and garment color. Curr Biol 17:1938-1942.

Bechert US, Southern S. 2002. In: Baer CK, editor. Monitoring environmental stress in African elephants (Loxodonta africana) through molecular analysis of stress-activated proteins. Milwaukee, WI: Proc Am Assoc Zoo Vet Ann Conf. p 249-253.

Blake S, Deem SL, Strindberg S, Maisels F, Momont L, Isaa I-B, Douglas-Hamilton I, Karesh WB, Kock MD. 2008. Roadless wilderness area determines forest elephant movements in the Congo basin. PLOS One 3: e3546.

Blom A, van Zalinge R, Mbea E, Heitkonig IMA, Prins HHT. 2004. Human impact on wildlife populations within a protected Central African forest. African J Ecol 42:23-31.

Broom D, Johnson J. 1993. Stress and animal welfare. London, UK: Chapman \& Hall.

Brown JL, Wemmer CM, Lehnhardt JL. 1995. Urinary cortisol analysis for monitoring adrenal activity in elephants. Zoo Biol 14:533-542.

Brown JL, Walker SL, Moeller T. 2004. Comparative endocrinology of cycling and non-cycling Asian (Elephas maximus) and African (Loxodonta africana) elephants. Gen Comp Endoc 136:360-370.

Brown JL, Wielebnowski N, Cheeran J. 2008. Challenges with identifying and evaluating pain, distress and suffering in elephants. In: Wemmer C, Christen C, editors. Elephants and ethics. Baltimore, MD: John Hopkins University Press. p 121-148.

Burke T, Page B, van Dyk G, Millspaugh J, Slotow R. 2008. Risk and ethical concerns of hunting male elephant: behavioral and physiological assays of the remaining elephants. PLOS One 3:e2417.

Burks KD, Mellen JD, Miller GW, Lehnhardt J, Weiss A, Figueredo AJ, Maple TL. 2004. Comparison of two introduction methods for African elephants (Loxodonta africana). Zoo Biol 23:109-126.

Burman OH, Parker RM, Paul ES, Mendl M. 2008. Sensitivity to reward loss as an indicator of animal emotion and welfare. Biol Lett 4:330-333.

Carlstead K, Fraser J, Bennett C, Kleiman DG. 1999. Black rhinoceros (Diceros bicornis) in U.S. zoos: II. Behavior, breeding success, and mortality in relation to housing facilities. Zoo Biol 18:35-52.

Cavigelli SA, Yee JR, McClintock MR. 2005. Infant temperament predicts life span in female 
rats that develop spontaneous tumors. Horm Behav 50:454-462.

Cerling TE, Wittemyer G, Rasmussen HB, Vollrath F, Cerling CE, Robinson TJ, DouglasHamilton I. 2006. Stable isotopes in elephant hair document migration patterns and diet changes. PNAS 103:371-373.

Chamaillé-Jammes S, Fritz H, Valeix M, Murindagomo F, Clobert J. 2008. Resource variability, aggregation and direct density dependence: the local regulation of an African elephant population. J Anim Ecol 77:135-144.

Chatkupt TT, Sollod AE. 1999. Elephants in Thailand: determinants of health and welfare in working populations. J Appl Anim Welf Sci 2:187-203.

Clubb R, Mason G. 2002. A review of the welfare of elephants in European zoos. Horsham, UK: RSPCA.

Clubb R, Lee P, Mar KU, Moss C, Rowcliffe M, Mason GJ. 2008. Compromised survivorship in zoo elephants. Science 322:1649.

Clubb R, Lee P, Mar KU, Moss C, Rowcliffe M, Mason GJ. 2009. Fecundity and population viability in female zoo elephants: problems and possible solutions. Anim Welf.

Cooper J, Mason G, Raj M. 1998. Determination of aversion to carbon dioxide in farmed mink (Mustela vison). Vet Rec 143:359-361.

Core S, Miller S, Widowski T, Mason G. 2009. Eye white percentage as a predictor of temperament in beef cattle. J Anim Sci 1910 (advance publication online Feb. 2009). DOI:10.2527/ jas.2008-1554

Crawley J. 2007. What's wrong with my mouse? 2nd edition. New York, NY: Wiley-Liss.

Danbury TC, Weeks CA, Waterman-Pearson AE, Kestin SC, Chambers JP. 2000. Self-selection of the analgesic drug carprofen by lame broiler chickens. Vet Rec 146:307-311.

Danese A, Pariante CM, Caspi A, Taylor A, Poulton R. 2007. Childhood maltreatment predicts adult inflammation in a life course. PNAS 104:1319-1324.

Dathe HH, Kuckelkorn B, Minneman D. 1992. Salivary cortisol assessment for stress detection in the Asian elephant (Elephas maximus): a pilot study. Zoo Biol 11:285-289.

Davenport MD, Tiefenbacher S, Lutz CK, Novak MA, Meyer JS. 2006. Analysis of endogenous cortisol concentrations in the hair of rhesus macaques. Gen Comp Endocrinol 147:255-261.

Dawkins MS. 1980. Animal suffering: the science of animal welfare. London: Chapman and Hall.

Dawkins MS. 1983. Battery hens name their price: consumer demand theory and the measurement of ethological 'needs'. Anim Behav 31: 1195-1205.

Dawkins MS. 1990. From an animal's point of view: motivation, fitness and animal welfare. Behav Brain Sci 13:1-61.
Dehnhard M. 2007. Characterisation of the sympathetic nervous system of Asian (Elephas maximus) and African (Loxodonta africana) elephants based on urinary catecholamine analyses. Gen Comp Endocrinol 151:274-284.

Derby P. 2008. Changes in social and biophysical environment yield improved physical and psychological health for captive elephants. In: Forthman DL, Kane L, Waldau PF, editors. An elephant in the room: the science and well being of elephants in captivity. North Grafton, MA: Tufts University Cummings School of Veterinary Medicine's Center for Animals and Public Policy. p 211-220.

Edkins MT, Kruger LM, Harris K, Midgley JJ. 2008. Baobabs and elephants in Kruger National Park: nowhere to hide. Afr J Ecol 46:119-125.

Exner C, Zanella AJ. 1999. Salivary cortisol in elephants - a pilot study. In: Bøe KE, Bakken M, Braastad BO, editors. Proceedings of the 33rd International Congress of the International Society for Applied Ethology. Lillehammer, Norway, 17-21 August 1999.

Foley CAH, Papageorge S, Wasser SK. 2001. Noninvasive stress and reproductive measures of social and ecological pressures in free-ranging African elephants. Cons Biol 15:1134-1142.

Friend T. 1999. Behavior of picketed circus elephants. Appl Anim Behav Sci 62:73-88.

Ganswindt A, Palme R, Heistermann M, Borragan S, Hodges JK. 2003. Non-invasive assessment of adrenocortical function in the male African elephant (Loxodonta africana) and its relation to musth. Gen Comp Endoc 134:156-166.

Ganswindt A, Rasmussen HB, Heistermann M, Hodges JK. 2005. The sexually active states of free-ranging male African elephants (Loxodonta africana): defining musth and non-musth using endocrinology, physical signals, and behavior. Horm Behav 47:83-91.

Gobush KS, Mutayoba BM, Wasser SK. 2008. Long-term impacts of poaching on relatedness, stress physiology, and reproductive output of adult female African elephants. Conserv Biol 22:1590-1599.

Harding E, Paul E, Mendl M. 2004. Animal behavior: cognitive bias and affective state. Nature 427:312.

Harris M, Sherwin S, Harris S. 2008. The welfare, housing and husbandry of elephants in UK zoos: Final report, University of Bristol. DEFRA Science and Research Project WC05007.

Hermes R, Hildebrandt TB, Göritz F. 2004. Reproductive problems directly attributable to long-term captivity: asymmetric reproductive aging. Anim Reprod Sci 82-83:49-60.

Hermes R, Saragusty J, Shaftenaar W, Göritz F, Schmitt DL, Hildebrandt TB. 2008. Obstetrics in elephants. Theriogenolgy 70:131-144.

Hunt KE, Wasser SK. 2003. Effect of long-term preservation methods on fecal glucocorticoid concentrations of grizzly bear and African elephant. Physiol Biochem Zool 76:918-928. 
Jones EKM, Wathes CM, Webster AJF. 2003. Strength of motivation of broiler chickens to seek fresh air after exposure to atmospheric ammonia. Br Poult Sci 44:S6-S7.

Kiecolt-Glaser JK, McGuire L, Robles TF, Glaser R. 2002. Emotions, morbidity, and mortality: new perspectives from psychoneuroimmunology. Annu Rev Psychol 53:83-107.

Kiecolt-Glaser JK, Preacher KJ, MacCallum RC, Atkinson C, Malarkey WB, Glaser R. 2003. Chronic stress and age-related increases in the proinflammatory cytokine IL-6. PNAS 100: 9090-9095.

King LE, Douglas-Hamilton I, Vollrath F. 2007. African elephants run from the sound of disturbed bees. Curr Biol 17:R832-R833.

Kramer B, Teixeira M, Hattingh J. 1991. The histology of the adrenal gland of the African elephant (Loxodonta africana). SA J Zool 26:193-198.

Kurt F, Garaï M. 2001. Stereotypies in captive Asian elephants - a symptom of social isolation. Abstracts of the International Elephant and Rhino Research Symposium, Vienna, Austria. Schuling, Muenster.

Laws N, Ganswindt A, Heistermann M, Harris M, Harris S, Sherwin CM. 2007 A case study: faecal corticosteroid and behavior as indicators of welfare during relocation of an Asiatic elephant. J Appl Anim Welf Sci 10:349-358.

Leng G, Mansfield S, Bicknell RJ, Brown D, Chapman $\mathrm{C}$, Hollingsworth $\mathrm{S}$, Ingram $\mathrm{CD}$, Marsh MI, Yates JO, Dyer RG. 1987. Stressinduced disruption of parturition in the rat may be mediated by endogenous opioids. J Endocrinol 114:247-252.

Limin F, Li Z. 2005. Habitat selection by Asian elephant (Elephas maximus) in Xishuangbann, Yunna, China. Acta Theriologica Sinica 25, 229-236 (in Chinese; abstract in English).

Mar KU. 2007. The demography and life history strategy of timber elephants in Myanmar [dissertation]. London: University College London.

Mason G. 2006. Stereotypic behavior: fundamentals and applications to animal welfare and beyond. In: Mason G, Rushen J, editors. Stereotypies in captive animals, 2nd edition. Wallingford, UK: CAB International. p 325-356.

Mason G, Cooper J, Clarebrough C. 2001. The welfare of fur-farmed mink. Nature 410:35-36.

Mason G, Hampton C, Wilson D, Würbel H. 2004. Chromodacryorrhoea scores as a noninvasive means of assessing stress and disturbance in laboratory rats. ATLA 32:153-159.

Mason G, Clubb R, Latham N, Vickery S. 2007. How and why should we use enrichments to tackle stereotypic behavior? Appl Anim Behav Sci 102:163-188.

Mason G, Ware N, Dallaire J. 2009. The smell of fear: a 'low tech' method for collecting and assaying stress odours in laboratory rodents. Anim Welf.

Mason GJ. 1991. Stereotypies and suffering. Behav Proc 25:103-115.
Mason GJ, Latham N. 2004. Can't stop, won't stop: is stereotypy a reliable animal welfare indicator? Anim Welf 13:S57-S69.

Mason GJ, Mendl M. 1993. Why is there no simple way of measuring animal welfare? Anim Welf 2:301-320.

Matheson SM, Asher L, Bateson M. 2008. Larger, enriched cages are associated with 'optimistic' response biases in captive European starlings (Sturnus vulgaris). Appl Anim Behav Sci 109:374-383.

Mellor CL, Croney CC, Shepherdson D. 2007. Effects of rubberized flooring on Asian elephant behavior in captivity. Zoo Biol 26:51-61.

Menargues A, Urios V, Mauri M. 2008. Welfare assessment of captive Asian elephants (Elephas maximus) and Indian rhinoceros (Rhinoceros unicornis) using salivary cortisol measurement. Anim Welf 17:305-312.

Mikota SK. 2008. Stress, disease and tuberculosis in elephants. In: Forthman DL, Kane L, Waldau PF, editors. An elephant in the room: the science and well being of elephants in captivity. North Grafton, MA: Tufts University Cummings School of Veterinary Medicine's Center for Animals and Public Policy. p 79-91.

Millspaugh J. 2003. Use of faecal stress measures on conservation biology research: a case study of elephants in South Africa. Seminar to the Kansas State University Wildlife Society, November 14, 2003. http://www.ksu.edu/wildlife/wildactsjoshmillspaugh.htm.

Millspaugh JJ, Burke T, Van Dyk G, Slotow R, Washburn BE, Woods RJ. 2007. Stress response of working African elephants to transportation and safari adventures. J Wildl Manage 71:1257-1260.

Moussaieff Masson J, McCarthy S. 1995. When elephants weep. London: Vintage.

O'Connell-Rodwell CE, Wood JD, Kinzley C, Rodwell TC, Poole JH, Puria S. 2007. Wild African elephants (Loxodonta africana) discriminate between familiar and unfamiliar conspecific seismic alarm calls. J Accoust Soc Am 122: 823-831.

Oliveira CA, Felippe EC, Chelini MO. 2008. Serum cortisol and progestin concentrations in pregnant and non-pregnant Asian elephants (Elephas maximus). Res Vet Sci 84:361-363.

Pedersen CA, Boccia ML. 2002. Oxytocin links mothering received, mothering bestowed and adult stress responses. Stress 5:259-267.

Poole JH, Granli PK. 2009. Visual and tactile signals of elephants. In: Moss CJ, Croze HJ, editors. The amboseli elephants: a long-term perspective on a long-lived. Mammal. Chicago: University of Chicago Press.

Rajapaksha E, Harris MJ, Sherwin CM, Harris S. 2006. Development and assessment of a gait scoring system for zoo elephants. In: Mendl M, Bradshaw JWS, Burman OHP, Butterworth A, Harris MJ, Held SDE, Jones SM, Littin KE, Main DCJ, Nicol CJ, Parker RMA, Paul ES, 
Richards G, Sherwin CM, Statham PTE, Toscano MJ, Warriss PD, editors. Proc 40th Int Congress International Society for Applied Etholog. Bristol, UK. p 56

Sandem AI, Braastad BO, Boe KE. 2002. Eye white may indicate emotional state on a frustration-contentedness axis in dairy cows. Appl Anim Behav Sci 79:1-10.

Schulte BA, Freeman EW, Goodwin TE, HollisterSmith J, Rasmassen LEL. 2007. Honest signaling through chemical by elephants, with applications for care and conservation. Appl Anim Behav Sci 102:344-363.

Sikes SK. 1968. Habitat stress and arterial disease in elephants. Oryx 9:286-292.

Slotow R. 2002. Stressed Elephant Dung, Brucellosis in Buffalo and Lions. Interview on 'Earthbeat'. Broadcast on October 26, 2002. http://www.abc. net.au/rn/science/earth/stories/s707995.htm.

Sobrinho LG. 1998. Emotional aspects of hyperprolactinaemia. Psychother Psychosom 67:133-139.

Sobrinho LG. 2003. Prolactin, psychological stress and environment in humans: adaptation and maladaptation. Pituitary 6:35-39.

Soltis J, Leighty KA, Wesolek CM, Savage A. 2009. The expression of affect in African elephant (Loxodonta africana) rumble volcaizations. J Comp Psychol doi: 10.1037/a0015223.

Stead SK, Meltzer DGA, Palme R. 2000. The measurement of glucocorticoid concentrations in the serum and faeces of captive African elephants (Loxodonta africana) after ACTH stimulation. J S Afr Vet Assoc 71:192-196.

Sukumar R. 2003. The living elephants: evolutionary ecology, behavior, and conservation. Oxford, UK: Oxford University Press.

Susskind JM, Lee DH, Cusi A, Feiman R, Grabski W, Anderson AK. 2008. Expressing fear enhances sensory acquisition. Nat Neurosci 11:843-850.

Szdzuy K, Dehnard M, Strauss G, Eulenberger K, Hofer H. 2006. Behavioral and endocrinological parameters of female African and Asian elephants Loxodonta africana and Elephas maximus in the peripartal period. Int Zoo Yearbk 40: $41-50$.

Terio KA, Marker L, Munson L. 2004. Evidence for chronic stress in captive but not free-ranging cheetahs (Acinonyx jubatus) based on adrenal morphology and function. $\mathbf{J}$ Wildl Dis 40:259-266.

Toates F. 1997. Stress: conceptual and biological aspects. New York, NY: John Wiley \& Sons.

Touma C, Sachser N, Möstl E, Palme R. 2003. Effects of sex and time of day on metabolism and excretion of corticosterone in urine and feces of mice. Gen Comp Endoc 130:267-278. van der Kolk JH, van Leeuwen JPTM, van den Belt AJM, van Schaik RHN, Schaftenaar W. 2008. Subclinical hypocalcaemia in captive Asian elephants (Elephas maximus). Vet Rec 162:475-479.

Veasey JS, Waran NK, Young RJ. 1996a. On comparing the behavior of zoo housed animals with wild conspecifics as a welfare indicator. Anim Welf 5:13-24.

Veasey JS, Waran NK, Young RJ. 1996b. On comparing the behavior of zoo housed animals with wild conspecifics as a welfare indicator using the giraffe as a model. Anim Welf 5:139-153.

Viljoen JJ, Ganswindt A, du Toit JT, Langbauer WR. 2008. Tranlocation stress and faecal glucocorticoid metabolite levels in free-ranging African savannah elephants. S Afr J Wild Res 38:146-152.

von Borell E, Dobson H, Prunier A. 2007. Stress, behavior and reproductive performance in female cattle and pigs. Horm Behav 52:130-138.

Wall J, Douglas-Hamilton I, Vollrath F. 2006. Elephants avoid costly mountaineering. Curr Biol 16:527-529.

Warburton H, Mason G. 2003. Is out of sight, out of mind? The effects of resource cues on motivation in the mink (Mustela vison). Anim Behav 65:755-762.

Wasser SK, Hunt KE, Brown JL, Cooper K, Crockett CM, Bechert U, Millspaugh JJ, Larson S, Monfort SL. 2000. A generalized fecal glucocorticoid assay for use in a diverse array of non-domestic mammalian and avian species. Gen Comp Endoc 120:260-275.

Weary DM, Braithwaite LA, Fraser D. 1998. Vocal response to pain in piglets. J Appl Anim Behav Sci 56:161-172.

Weibull AC, Eriksson H. 1998. Short-term gland secretion in the African elephant: tourist disturbance or social interactions as source for secretion? Afr J Ecol 36:360-367.

Wielebnowski NC, Carlstead K, Brown JL. 2002. Noninvasive assessment of adrenal activity associated with husbandry and behavioral factors in the North American clouded leopard population. Zoo Biol 21:177-198.

Wingfield JC, Sapolsky RM. 2003. Reproduction and resistance to stress: when and how. J Neuroendocrinol 15:711-724.

Yadav VK, Natrajan T, Medhamurthy R. 2001. Increased stress-activated protein kinase activity during PGF2alphas-mediated apoptotic cell death in buffalo corpus lutuem. Proceedings XXV All India Cell Biology Conference, Bangalore, India. p A59. 